\title{
EVALUATION OF THE EFFECT OF THE HIGH INSERTION TORQUE ON THE IMMEDIATELY LOADED DENTAL IMPLANTS (CLINICAL \& RADIOGRAPHIC STUDY)
}

\author{
Gawish $\mathrm{A}^{1} B D S$, Osman $\mathrm{S}^{2} P h D$, Shokry $\mathrm{M}^{3} P h D$
}

\begin{abstract}
Introduction: The ideal insertion torque values for placing dental implants to be immediately loaded is unknown, therefore it may be useful to evaluate the effect of insertion torque values on immediately loaded dental implants.

Objectives: was to evaluate clinically and radiographically the placement of immediately loaded single implants inserted with high insertion torque $(>70$ N.cm).

Materials and Methods: This study was conducted on twelve patients divided in to two groups (study group and control group) with missed mandibular posterior teeth, Zimmer Swissplus Implants were inserted using Aseptico motor implant system, insertion torque was measured digitally. In the control group implants were inserted with medium torque $(25-35 \mathrm{~N} . \mathrm{cm})$ while in the study group implants were inserted with high torque $(>70$ N.cm).
\end{abstract}

Results: There was a statistically significant increase in bone density around the implants in the study group at 6 months postoperative compared with the control group.

Conclusions: the use of high insertion torque (up to $70 \mathrm{~N} . \mathrm{cm}$ ) neither prevented osseointegration nor increased marginal bone resorption around tapered multithreaded dental implants placed in posterior mandible. Also there is statistically significant correlation between insertion torque and bone density around implants placed in posterior mandible.

Key Words: Dental implants, Insertion torque, Immediate loading.

1- B.D.S (2002). Department of Oral and Maxillofacial Surgery, Faculty of Dentistry, University of Alexandria.

2- Professor at Department of Oral and Maxillofacial Surgery, Faculty of Dentistry, Alexandria University.

3- Assistant Professor of Oral and Maxillofacial Surgery, Faculty of Dentistry, Beirut Arab University

\section{INTRODUCTION}

Implant stability depends on the direct mechanical connection between implant surface and the surrounding bone and can be divided into primary and secondary stability (1).

The goal of achieving primary stability at the time of implant placement is to limit excessive micromotion at the bone-implant interface, which could fracture regenerating bone and prevent osseointegration (2-4).

The use of a slightly narrower final drill with a tapered implant design has been often associated with elevated insertion torque (IT) (5-6) and localized bone compression (7). Both of these factors may help to increase primary implant stability.

Factors such as bone density, length, width, type of implant and surgical technique may interfere with primary implant stability (8).

The clinical measurement that assesses primary implant stability is IT. High IT indicates that the implant is well fixed and mechanically stable within the bone tissue (9).

Implant stability can be measured by non-invasive clinical test methods, one of these quantitative methods is the insertion torque described by Johansson and Strid (10).
This method records the torque required to place the implant and provides valuable information about the local bone quality.

Measurement of the cutting resistance of the jaw bone (insertion torque) (measured in Newton-centimeters), where $1 \mathrm{Ncm}$ is the torque generated by a force of $1 \mathrm{~N}$ acting on a lever of $1 \mathrm{~cm}$ in length is performed intraoperatively $(11,12)$.

IT corresponds to a combination of the cutting friction of the tip of the implant in the bone, and the friction between the implant surface and the hole in the bone. If the hole is narrow or the bone quality is high the torque will be higher. The torque will also depend on how sharp the cutting tip of the implant is, on the surface properties of the implant, on the lubrication of the preparation (blood) and also on the design of the implant itself. For instance if the preparation is cylindrical and the implant is tapered, the insertion torque will be higher. May be most important is the diameter of the implant, a narrow implant will have lower insertion torque than a wide implant in the same bone (13).

The aim of this study was to evaluate the outcome of immediately loaded single implants inserted with high insertion torques (>70 N.cm). 


\section{MATERIALS AND METHODS}

A total of 15 implants were placed in the mandibular posterior region. Each patient was informed about the study's aims and gave informed consent.

\section{Inclusion criteria}

Age ranged between 25 and 40 years, good oral hygiene, mandibular posterior missing teeth, suitable inter-occlusal distance at the edentulous area to allow implant placement and its fixed prosthesis, adequate bone quantity and quality, acceptance of treatment plan and signature of informed consent.

\section{Exclusion criteria}

Radiotherapy at the head/neck region within the last 12 months, uncontrolled diabetes, pregnancy, poor oral hygiene and/or motivation, drug or alcohol abuse, active inflammation/infection in the sites of implant insertion, smoking $>10$ cigarettes/day and severe bruxism or clenching.

Patients were divided to two groups each group containing 6 patients (control group and study group), Zimmer SwissPlus implant system was used in this study (Zimmer implant system company 1800 West Center Street Warsaw, USA). A preoperative orthopantomogram and cone beam computerized tomography (CBCT) (Kodak CS 9300 CBCT machine) with software (OnDemand 3d app) (Fig.1) were done for patients of the two groups.

\section{Surgical technique}

Inferior alveolar nerve block and long buccal nerve block local anesthesia were given, the surgical field was then cleaned with a tincture iodine swab.

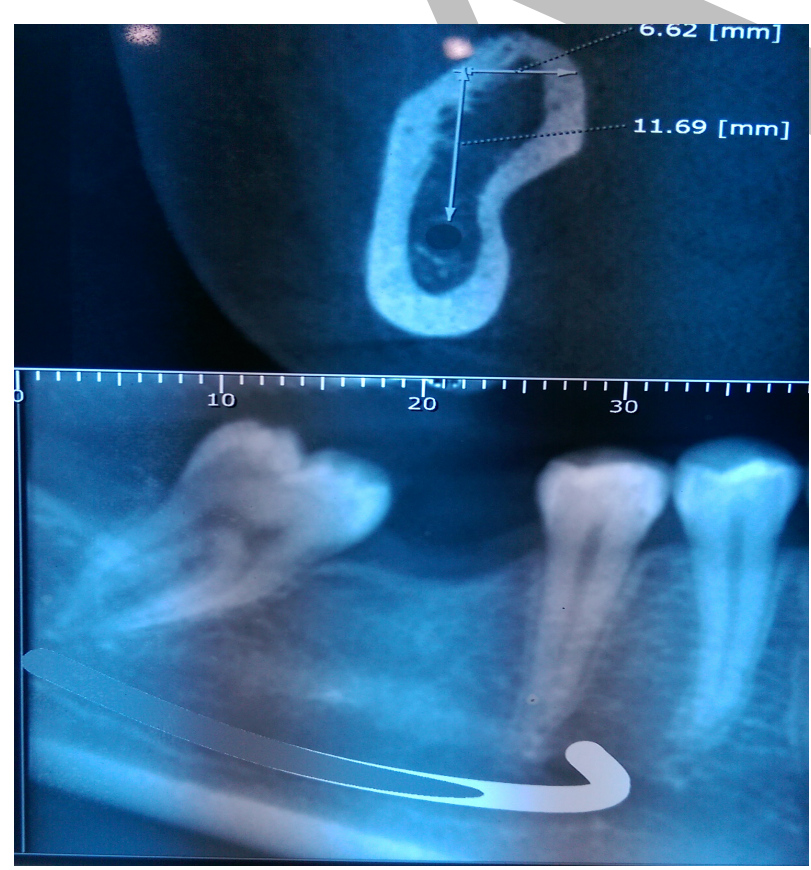

Fig. 1: Preoperative CBCT done for patient.
The flap design used was three incision-lines flap (Pyramidal flap), to adequately expose the surgical field which was done using Bard-Parker scalpel number 15, then full thickness mucoperiosteal flap was reflected, the osteotomy was prepared by drilling using pilot drill followed by the successive drills till reaching the final drill which corresponds to $0.5 \mathrm{~mm}$ less than the diameter of the selected implant. Drilling was made under copious external irrigation by normal saline as cooling system, depth of the drilling was monitored using depth gauge, and parallelism was checked using paralleling pins.

After drilling and debridement, the implant was held by its cover and inserted into the osteotomy site and screwed using Aseptico implant motor system (Aseptico dental equipment 8333 216th Street SE Woodinville, USA) (Fig.2), the insertion torque was adjusted digitally according to resistance of bone which corresponds to bone quality, the inserted implants were then grouped according to insertion torque.

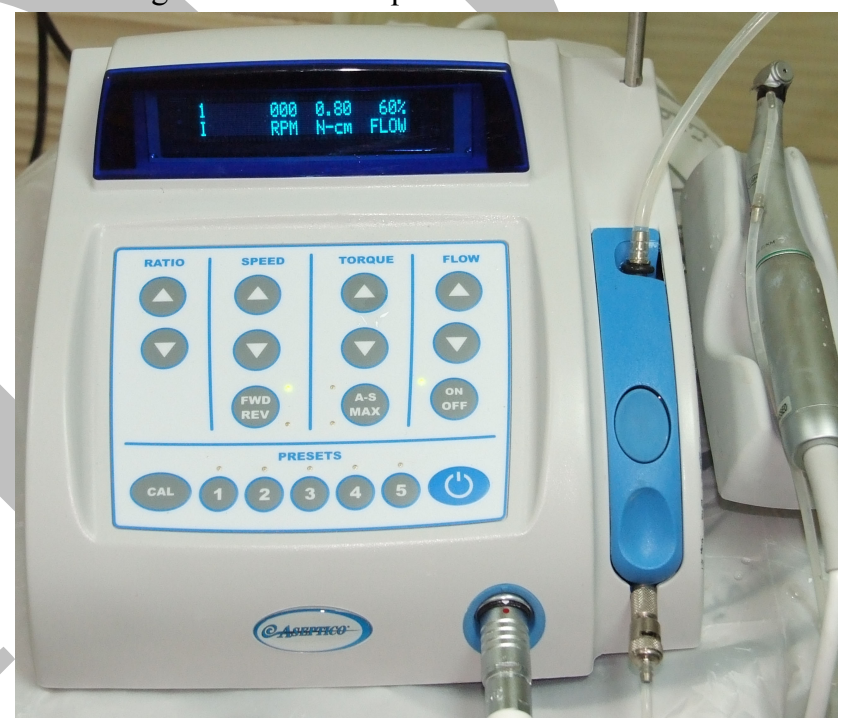

Fig. 2: Aseptico implant motor

Control group: Implants were inserted with medium insertion torque (25-35 N.cm) using Aseptico implant motor system, Study group: Implants were inserted with high torque (> 70 N.cm) using the same motor.

Immediate loading with ready-made acrylic crowns (Provyl, Dentsply ${ }^{\circledR}$, USA) which were prepared to be 2 $\mathrm{mm}$ free from occlusion and then placed using temporary cement. After 3 months temporary crowns were removed and final porcelain crowns were inserted.

Clinical follow up: All the patients in the two groups group 1 (control group) and group 2 (study group) were examined clinically for probing depth, papillary bleeding and implant mobility after implant placement immediately and at 3 and 6 months intervals. Mobility 
was tested using back and forth pressure of approximately 500 gm by two instrument handles.

Radiographic follow up: All the patients in the two groups were examined radiographically immediately postoperative by standardized periapical $\mathrm{x}$-ray films using XCP film holder to serve as a baseline for measurement (Fig.3), and after 3 and 6 months using periapical x-ray \& CBCT (Fig.4). Bone height was measured using CBCT software, while bone density was measured (in pixels) using Image J software.

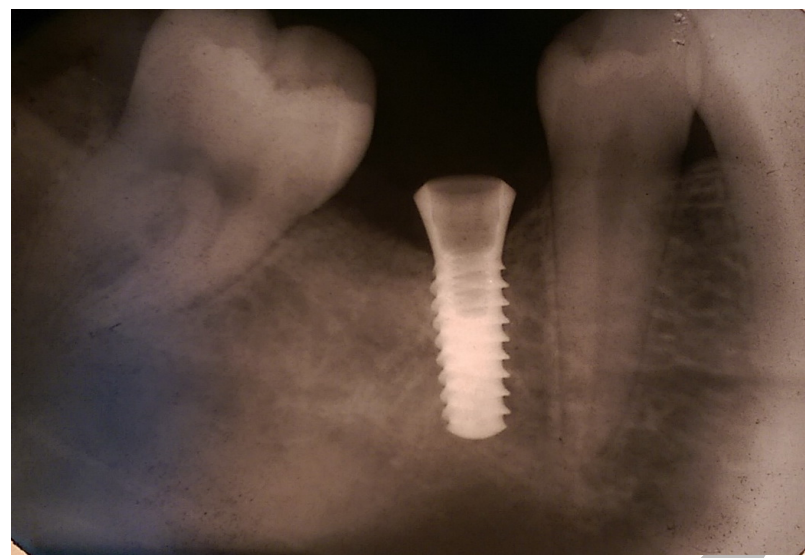

Fig.3: Immediate postoperative periapical x-ray.

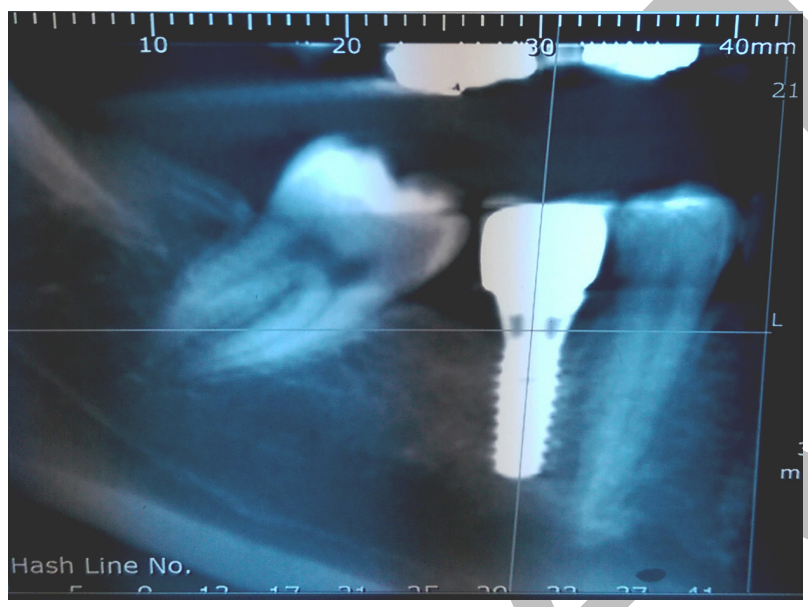

Fig. 4: Postoperative CBCT after 3 months.

\section{RESULTS}

This study was done on 15 implants placed in 12 patients, in all the studied patients the age ranged from 25- 40 years, with a mean of 27 years, the sizes of the implants used are shown in the table of sample distribution (Table 1).

After implant placement cases were classified into 2 groups ( $\mathrm{n}=$ implants). Group 1 (control) $(\mathrm{n}=7)$ : Implants were inserted with medium torque (25-35 N.cm). Group 2 (study) $(\mathrm{n}=8)$ : Implants were inserted with high torque $(>70 \mathrm{Ncm})$

As regards gender, there were 8 males and 4 females in all the studied patients with equal distribution in both groups, 4 males and 2 females in the study group and the same in the control group.

\begin{tabular}{|c|c|c|c|c|c|}
\hline & & Age & Gender & $\# \operatorname{Imp}$ & Implant size \\
\hline \multirow{6}{*}{$\begin{array}{c}\text { Group I } \\
\text { (Control } \\
\text { group) }\end{array}$} & Case 1 & 32 & male & 6 & $4.1 \mathrm{~mm} \times 12 \mathrm{~mm}$ \\
\hline & Case 2 & 28 & male & 5 & $4.1 \mathrm{~mm} \times 10 \mathrm{~mm}$ \\
\hline & Case 3 & 37 & male & 6 & $4.1 \mathrm{~mm} \times 12 \mathrm{~mm}$ \\
\hline & Case 4 & 26 & female & 7 & $4.1 \mathrm{~mm} \times 12 \mathrm{~mm}$ \\
\hline & Case 5 & 35 & male & 6 & $4.1 \mathrm{~mm} \times 12 \mathrm{~mm}$ \\
\hline & Case 6 & 27 & female & & $3.8 \mathrm{~mm} \times 12 \mathrm{~mm}$ \\
\hline \multirow{6}{*}{$\begin{array}{l}\text { Group } \\
\text { II } \\
\text { (Study } \\
\text { group) }\end{array}$} & Case 1 & 26 & female & 6 & $3.8 \mathrm{~mm} \times 10 \mathrm{~mm}$ \\
\hline & Case 2 & 33 & male & 7 & $4.1 \mathrm{~mm} \times 12 \mathrm{~mm}$ \\
\hline & Case 3 & 28 & male & 6 & $4.1 \mathrm{~mm} \times 12 \mathrm{~mm}$ \\
\hline & Case 4 & 35 & male & 5 & $4.1 \mathrm{~mm} \times 10 \mathrm{~mm}$ \\
\hline & Case 5 & 37 & male & 56 & $\begin{array}{l}3.8 \mathrm{~mm} \times 10 \mathrm{~mm} \\
4.1 \mathrm{~mm} \times 12 \mathrm{~mm}\end{array}$ \\
\hline & Case 6 & 34 & female & 7 & $4.1 \mathrm{~mm} \times 10 \mathrm{~mm}$ \\
\hline
\end{tabular}

Table 1: Showing sample distribution in the current study.

\section{Clinical Follow Up:}

Probing pocket depth: Mean probing depth values and standard deviation for both groups were measured immediate post-operative, at 3 months and 6 months. The difference in probing depth values was found to be statistically insignificant $(Z=1.206$, $p$-value $=0.254)$.

Papillary bleeding index (PBI): The intensity of any bleeding provoked was recorded on a $0-4$ scale (Muhlemann 1981) (14). The difference in (PBI) readings between the two groups was found to be statistically insignificant $(\mathrm{LR}=2.773$, $\mathrm{p}$-value $=0.428)$.

Mobility: According to the clinical implant mobility scale (0-4 scale) Mckinney and Koth (15) none of the implants of both groups showed any signs of mobility throughout the evaluation period except one implant in group 2 which showed mobility after two weeks and was removed and excluded from statistical analysis. i.e. mobility score was 0 .

Radiographic results

Evaluation of marginal Bone level around the implant: Mean marginal bone level values and standard deviation at 3 months and 6 months of both groups are shown in (Table2, Fig.5)

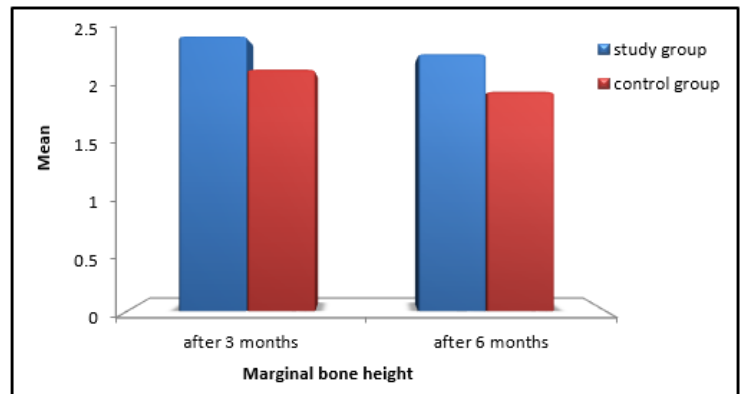

Fig. 5: Comparison between the study group and the control group according to the marginal bone height. 


\begin{tabular}{|c|c|c|c|}
\hline $\begin{array}{c}\text { Marginal } \\
\text { bone height } \\
(\mathbf{m m})\end{array}$ & $\begin{array}{c}\text { Control group } \\
(\mathrm{n}=7)\end{array}$ & $\begin{array}{c}\text { Study group } \\
(\mathrm{n}=7)\end{array}$ & $\begin{array}{c}\text { Test of } \\
\text { significance } \\
(\mathrm{p} \text { value })\end{array}$ \\
\hline $\begin{array}{c}\text { After 3 } \\
\text { months }\end{array}$ & $1.50-2.60$ & $2.00-3.00$ & $\mathrm{Z}=1.431$ \\
Min-Max & $2.18 \pm 0.38$ & $2.48 \pm 0.30$ & $(0.19)$ \\
Mean \pm SD & & & \\
\hline $\begin{array}{c}\text { After 6 } \\
\text { months }\end{array}$ & $1.40-2.30$ & $2.00-2.80$ & $\mathrm{Z}=2.014$ \\
Min-Max & $1.98 \pm 0.30$ & $2.32 \pm 0.28$ & $(0.53)$ \\
Mean \pm SD & & & \\
\hline
\end{tabular}

Table (2): Comparison between the study group and the control group according to the marginal bone height. $\mathrm{Z}=$ Mann Whitney test $*$ Significant at $\mathrm{p} \leq 0.05$

At 3 months, the mean marginal bone level for control group was $2.18 \pm 0.38$ and the mean marginal bone level for study group was $2.48 \pm 0.30$. At 6 months, the mean marginal bone level for control group was $1.98 \pm 0.30$ and the mean marginal bone level for study group was $2.32 \pm 0.28$. This difference in marginal bone level values was found to be statistically insignificant $(\mathrm{Z}=2.014$, $\mathrm{p}$-value $=0.53)$

Evaluation of bone density around the implant: Mean peri-implant bone density values and standard deviation immediately post-operative, at 3 months and at 6 months of both groups are shown in (Table3, Fig.6)

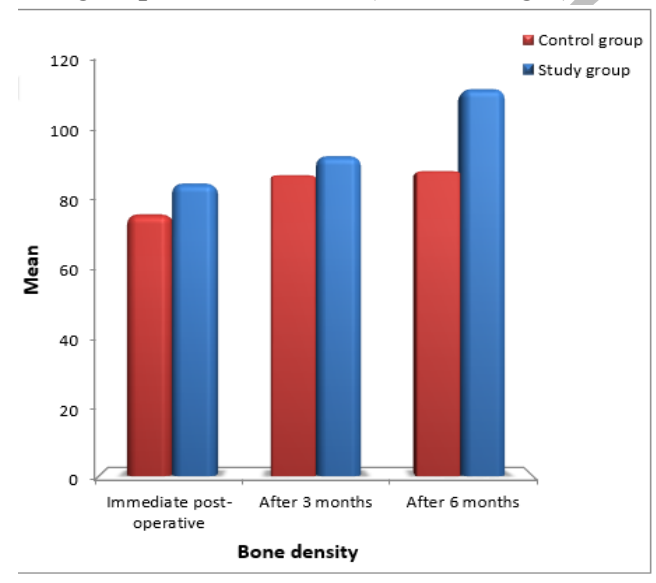

Fig. 6: Comparison between the study group and the control group according to the Bone density

\begin{tabular}{|c|c|c|c|}
\hline $\begin{array}{c}\text { Bone density } \\
\text { (Pixel) }\end{array}$ & $\begin{array}{c}\text { Control group } \\
(\mathrm{n}=7)\end{array}$ & $\begin{array}{c}\text { Study group } \\
(\mathrm{n}=7)\end{array}$ & $\begin{array}{c}\text { Test of } \\
\text { significance } \\
(\mathrm{p} \text { value })\end{array}$ \\
\hline $\begin{array}{c}\text { Immediate } \\
\text { post-operative }\end{array}$ & & & \\
Min-Max & $78.0-96.22$ & $81.18-141.10$ & $\mathrm{Z}=0.128$ \\
Mean $\pm \mathrm{SD}$ & $82.23 \pm 27.36$ & $85.23 \pm 39.03$ & $(0.548)$ \\
\hline 3 months & & & \\
Min-Max & $83.25-184.00$ & $85.14-172.12$ & $\mathrm{Z}=0.256$ \\
Mean $\pm \mathrm{SD}$ & $87.65 \pm 49.51$ & $90.22 \pm 35.20$ & $(0.312)$ \\
\hline 6 months & & & \\
Min-Max & $87.25-185.16$ & $93.15-204.13$ & $\mathrm{Z}=0.575$ \\
Mean $\pm \mathrm{SD}$ & $98.84 \pm 41.6$ & $112.8 \pm 39.53$ & $(0.008)^{*}$ \\
\hline
\end{tabular}

Table (3): Comparison between the study group and the control group according to the Bone density. $\mathrm{Z}=$ Mann Whitney test $*$ Significant at $\mathrm{p} \leq 0.05$

\section{Immediate post-operative}

The mean bone density value for control group was $82.23 \pm 27.36$, while the mean bone density value for study group was $85.23 \pm 39.03$. This difference in bone density values was found to be statistically insignificant $(\mathrm{Z}=0.128$, p-value $=0.548)$.

At 3 months, the mean bone density value for control group was $87.65 \pm 49.51$, while the mean bone density value for study group was $90.22 \pm 35.20$. This difference in bone density values was found to be statistically insignificant $(\mathrm{Z}=0.256$, $\mathrm{p}$-value $=0.0 .312)$.

At 6 months, the mean bone density value for control group was $98.84 \pm 41.6$, while the mean bone density value for study group II was $112.8 \pm 39.53$. This difference in bone density values was found to be statistically significant $(Z=0.575$, $p$-value $=0.008)$.

\section{DISCUSSION}

The successful outcome of any implant procedure depends on a series of patient-related and proceduredependent parameters, including general health conditions, biocompatibility of the implant material, the microscopic and macroscopic nature of the implant surface, the surgical procedure and the quality and quantity of the local bone (16).

Several other researchers have also reported that they sometimes had to use a manual wrench to finalize implant placement, and therefore had no mean to register the true peak insertion torque $(4,17)$.

In the present study implants were placed using Aseptico motor implant system which is rated up to 80 N.cm for implant applications and works with any conventional or mini implant system. The insertion torque can be adjusted and measured digitally.

In the present study, no negative effects of high insertion torque on marginal bone loss could be detected. It is possible that other more heterogeneous implant designs with marked steps and edges along the implant surface may result in bone resorption when using high insertion torque because of stress concentration.

Regarding the implant mobility, no detectable clinical mobility of anyone of the used implants was detected throughout the evaluation period. This was confirmed by radiographic evaluation that revealed the absence of periimplant radiolucency. This indicates proper osseointegration of all implants. The absence of implant mobility is considered to be the most important criteria for implant success in accordance with Porter and Von Fraunhofer in 2005 (18).

From our clinical evaluation throughout the follow up period which was extended up to six months, only one patient from group II complained from pain, tenderness and swelling after two weeks and the implant failed and excluded from the study, this was attributed to bad oral hygiene and patient negligence.

As regarding bone density around the implant it was measured by Image J software (Image J, U. S. National Institutes of Health, Bethesda, Maryland, USA) on serial 
periapical standardized radiographs made by long cone paralleling technique using XCP film holder. These standardized radiographs were taken immediately postsurgery and at 3 and 6 months follow up periods to detect changes in bone density around the implants. Both groups showed an increase in bone density from immediately after implant placement to three months and continued to increase at six months. Group II showed higher bone density values than group I immediately after implant placement and throughout the whole follow-up period, this difference was found statistically significant.

The increase in peri-implant bone density may be attributed to the immediate loading of implants of both groups. The effect of immediate loading on peri-implant bone density was demonstrated in a clinical study by Barone (19) in 2003 which compared immediately loaded implants in partially edentulous patients, the radiological assessments showed that the mean bone density was higher in the immediately loaded group than in the unloaded group, the differences between the two groups of oral implants were statistically significant. Thus it was concluded that immediate loading seems to increase the ossification of the alveolar bone around endosseous implants.

A recent study by Dorjpalam and Hee (20) in 2013 showed that the IT and initial stability increased according to the increase in the bone density, resulting in a strong positive correlation. In other words, the initial stability was shown to be highly dependent on the bone density. The IT also increased according to the thickness of the cortical bone, and a slight increase was observed for initial stability. This shows that the volume of high dense cortical bone affects the initial stability.

\section{CONCLUSIONS}

Within the limitations of this study, the following conclusions can be listed:

- The use of high insertion torque (up to 70 N.cm) neither prevented osseointegration nor increased marginal bone resorption around tapered multithreaded dental implants placed in posterior mandible.

- Based on the results of this study, the values of insertion torque do not affect bone healing, and there are no radiologic signs of bone necrosis for values of insertion torque above 70 N.cm.

- Immediate loading of dental implants have no adverse effects on osseointegration and may increase bone density around the implant.

\section{CONFLICT OF INTEREST}

The authors declare that they have no conflicts of interest.

\section{REFERENCES}

1. Roberts W, Bone dynamics of osseointegration, ankylosis, and tooth movement. J Indiana Dent Assoc
1999; 78: 24-32.

2. Szmukler-Moncler S, Piatelli A, Favero GA, Dubruille $\mathrm{JH}$. Considerations preliminary to the application of early and immediate loading protocols in dental implantology. Clin Oral Implants Res 2000; 11:12-25.

3. Brunski JB. In vivo bone response to biomechanical loading at the bone/dental-implant interface. Adv Dent Res 1999; 13:99-119.

4. Calandriello R,Tomatis M,Rangert B.Immediate functional loading of Brånemark system implants with enhanced initial stability: a prospective 1- to 2-year clinical and radiographic study. Clin Implant Dent Relat Res 2003; 5:10-20.

5. Nikellis I, Levi A, Nicolopoulos C. Immediate loading of 190 endosseous dental implants: a prospective observational study of 40 patients treatments with up to 2years data. Int $\mathrm{J}$ Oral Maxillofac Implants 2004; 19:116-23.

6. Skalak R, Zhao Y. Interaction of force-fitting and surface roughness of implants. Clin Implant Dent Relat Res 2000; 2:219-24.

7. Le Gall MG.Localized sinus elevation and osteocompression with single-stage tapered dental implants: technical note.Int J Oral Maxillofac Implants 2004; 19:431-7.

8. Sennerby L, Meredith N. Implant stability measurements using resonance frequency analysis: biological and biomechanical aspects and clinical implications. Periodontol 2000. 2008;47:51-66

9. Nedir R, Bischof M, Szmukler-Moncler S, Bernard JP, Samson J. Predicting osseointegration by means of implant primary stability. Clin Oral Implants Res 2004; 15: 520-8.

10. Johansson P, Strid KG. Assessment of bone quality from placement resistance during implant surgery. Int J Oral Maxillofac Implants. 1994;9:279-88

11. Friberg B, Sennerby L, Roos J, Johansson P, Strid C. Evaluation of bone density using cutting resistance measurements and microradiography. Clinical Oral Implants Research 1995; 6: 164-71.

12. Homolka P, Beer A, Birkfellner W, Nowotny R, Gahleitner A, Tschabitscher M. et al. Bone mineral density measurement with dental quantitative CT prior to dental implant placement in cadaver mandibles. Radiology 2002; 224: 247-52.

13. Degidi M, Daprile G, Piatelli A. Determination of primary stability: a comparison of the surgeon's perception and objective measurements. Int $\mathrm{J}$ Oral Implants. 2010; 25(3):558-61.

14. Muhlemann HR. Physiology and chemical mediators of gingival health. J Prev Dent 1977; 4: 6-20.Quoted from: Greenstein $\mathrm{G}$. The role of bleeding upon probing in the diagnosis of periodontal disease: A literature review. $\mathrm{J}$ Periodontol 1984; 55:684.

15. Mckinney R, Koth D, Steflik D. Clinical standards for dental implant. In. Clark jw (eds) clinical dentistry. Harperstown, Harper and Row. 1998; 1-11

16. Beer A, Gahleitner A, Holm A, Tschabitscher M, 
Homolka P. Correlation of insertion torques with bone mineral density from dental quantitative CT in the mandible. Clin. Oral Impl. Res. 2003; 14: 616-20.

17. Nkenke E, Hahn M, Weinzierl K, Radespiel-Tröger M, Neukam FW, Engelke K. Implant stability and histomorphometry: a correlation study in human cadavers using stepped cylinder implants. Clin Oral Implants Res. 2003; 14(5):601-9.

18. Porter J, Von Fraunhofer J. Success or failure of dental implants? A literature review with treatment considerations. General Dent 2005; 423-32.

19. Barone A, Covani U, Cornelini R, Gherlone E. Radiographic bone density around immediately loaded oral implants. Clin Oral Implants Res 2003; 14: 610-5.

20. Dorjpalam B, Hee N, Byung K. Evaluation of the correlation between insertion torque and primary stability of dental implants using a block bone test. J Periodontal Implant Sci 2013; 43:30-6.
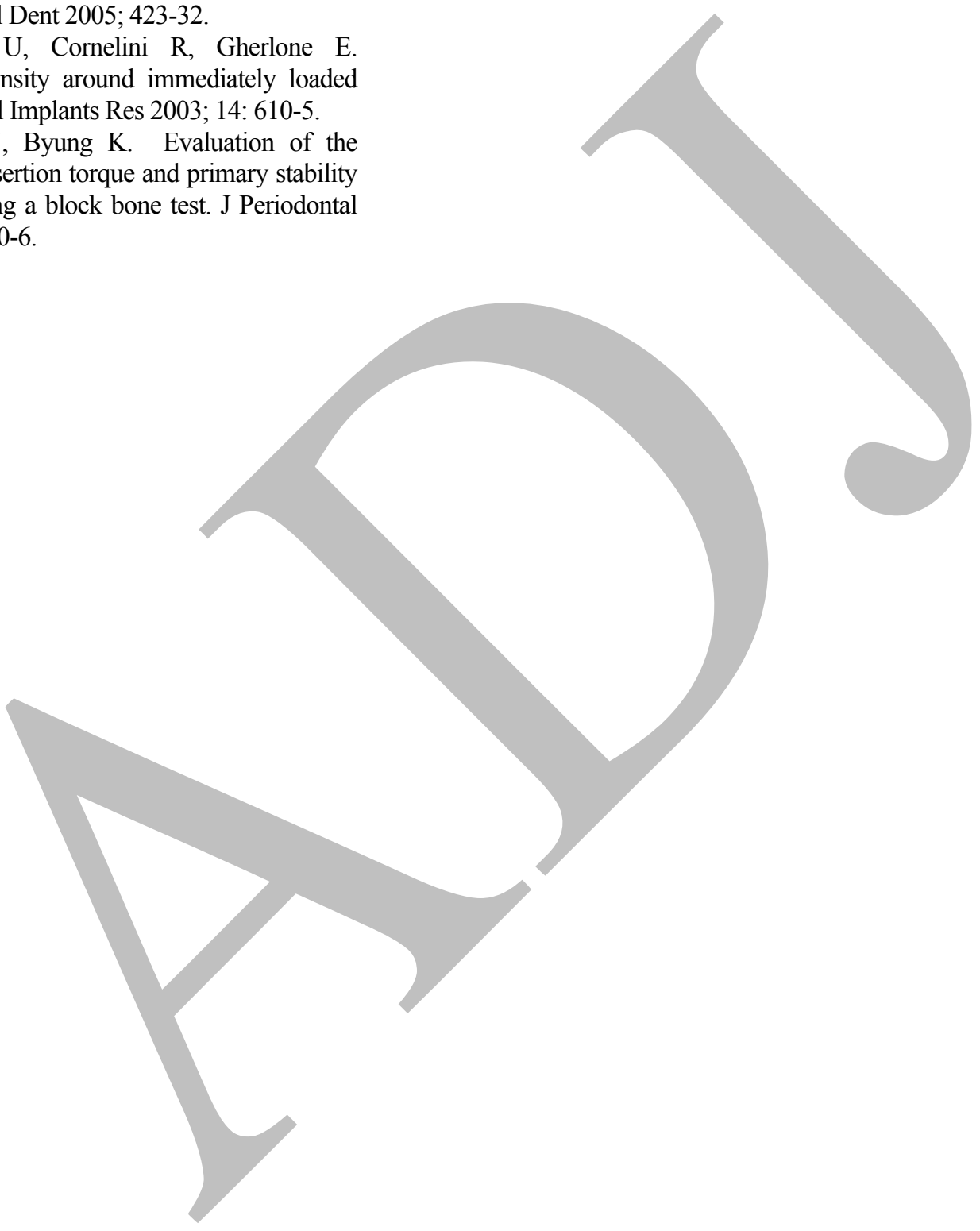